\title{
The European Union Committee of Experts on Rare Diseases (EUCERD): a new committee to help the European Commission advance in the field of rare disease policy
}

Antoni Montserrat Moliner ${ }^{1 *}$, Ségolène Aymé2

From 5th European Conference on Rare Diseases (ECRD 2010)

Krakow, Poland. 13-15 May 2010

The European Union Committee of Experts on Rare Diseases was formally established via the European Commission decision of 30 November 2009 (2009/ 872/EC). The EUCERD will aid the European Commission (EC) with the preparation and implementation of Community activities in the field of rare diseases, in cooperation and consultation with the specialised bodies in Member States, the relevant European authorities in the fields of research and public health action and other relevant stakeholders acting in the field. The EUCERD replaces the EC's Rare Diseases Task Force. Members of the EUCERD include representatives of: each Member State, patient organisations, the pharmaceutical industry, ongoing/past Community projects in the field of RD, ongoing/past RD projects financed by Community Framework Programmes for Research and Technological Development, DG Sanco, DG Research, DG Enterprise, Eurostat, and the ECDC. The EUCERD will foster exchanges of relevant experience, policies and practices between these parties and is charged with the following responsibilities: assisting the EC in the monitoring, evaluating and disseminating the results of measures taken at Community and national level in the field of rare diseases; contributing to the implementation and improvement of Community actions in the field; contributing to the preparation of EC reports on the implementation of the Commission Communication and the Council Recommendation; delivering opinions, recommendations or submitting reports to the EC either at the latter's request or on its own initiative; assisting the $\mathrm{EC}$ in international cooperation on matters relating to rare diseases; assisting the EC in drawing up guidelines, recommendations and any other action defined in the Commission Communication and in the Council Recommendation; providing an annual report of its activities to the EC. The EUCERD may establish temporary Working Groups including external experts for specific missions.

The Scientific Secretariat of the EUCERD is supported by an EC Joint Action.

\section{Author details}

${ }^{1}$ European Commission: Health and Consumers General-Directorate (SANCO), Luxembourg. ${ }^{2}$ Leader of the former Rare Disease Task Force (INSERM SC11 Orphanet), Paris, France.

Published: 19 October 2010

doi:10.1186/1750-1172-5-S1-028

Cite this article as: Moliner and Aymé: The European Union Committee of Experts on Rare Diseases (EUCERD): a new committee to help the European Commission advance in the field of rare disease policy. Orphanet Journal of Rare Diseases 2010 5(Suppl 1):O28.

\footnotetext{
*Correspondence: Antoni.Montserrat@ec.europa.eu

'European Commission: Health and Consumers General-Directorate (SANCO), Luxembourg

Full list of author information is available at the end of the article
} 